\title{
Synthesis, X-Ray Crystallography, Thermal Analysis, and DFT Studies of Ni(II) Complex with 1-Vinylimidazole Ligand
}

\author{
Fatih Şen, ${ }^{1}$ Ramazan Şahin, ${ }^{2}$ Muharrem Dinçer, ${ }^{3}$ Ömer Andaç, ${ }^{2}$ and Murat Taş ${ }^{4}$ \\ ${ }^{1}$ Department of Opticianry, Vocational High School of Health Services, Kilis 7 Aralik University, 79000 Kilis, Turkey \\ ${ }^{2}$ Department of Chemistry, Arts and Sciences Faculty, Ondokuz Mayıs University, 55139 Samsun, Turkey \\ ${ }^{3}$ Department of Physics, Arts and Sciences Faculty, Ondokuz Mayıs University, 55139 Samsun, Turkey \\ ${ }^{4}$ Department of Chemistry, Arts and Sciences Faculty, Giresun University, 28100 Giresun, Turkey
}

Correspondence should be addressed to Fatih Şen; fatihsen55@gmail.com

Received 12 September 2013; Revised 23 December 2013; Accepted 11 January 2014; Published 14 April 2014

Academic Editor: Hasan Küçükbay

Copyright (C) 2014 Fatih Şen et al. This is an open access article distributed under the Creative Commons Attribution License, which permits unrestricted use, distribution, and reproduction in any medium, provided the original work is properly cited.

\begin{abstract}
The paper presents a combined experimental and computational study of hexa(1-vinylimidazole) Ni(II) perchlorate complex. The complex was prepared in the laboratory and crystallized in the monoclinic space group P21/n with $a=8.442(5), b=13.686(8)$, $c=16.041(9) \AA, \alpha=\gamma=90, \beta=96.638(5)$, and $Z=1$. The complex has been characterized structurally (by single-crystal X-Ray diffraction) and its molecular structure in the ground state has been calculated using the density functional theory (DFT) methods with 6-31G(d) and LanL2DZ basis sets. Thermal behaviour and stability of the complex were studied by TGA/DTA analyses. Besides, the nonlinear optical effects (NLO), molecular electrostatic potential (MEP), frontier molecular orbitals (FMO), and the Mulliken charge distribution were investigated theoretically.
\end{abstract}

\section{Introduction}

Imidazole was first reported in 1858, although various imidazole derivatives had been discovered as early as the $1840 \mathrm{~s}$ [1]. Derivatives of imidazole represent a class of heterocyclic compounds of great importance. Both imidazole and its derivatives have found widespread applications in industry and pharmacy [2-5]. For example, imidazole has been used extensively as a corrosion inhibitor on certain transition metals, such as copper in industry [1], and also the substituted imidazole derivatives are valuable in treatment of many systemic fungal infections in pharmacy [6]. The imidazole ligand is of particular interest due to its important role in many biological systems, especially as the side group in histidine which plays an essential role in the active motif of many enzymes [7]. Imidazole in polymers has traditionally been utilized in a variety of applications such as immobilized catalysts $[8,9]$, redox reactions [10], water purification $[11,12]$, hydrometallurgy/metal recovery $[13,14]$, and ion and proton conductors [15].
Imidazoles are useful ligands in coordination chemistry and the synthesis of the compounds containing the imidazole ring is an important area of scientific investigation [1619]. Numerous complexes derived from $d$-block metals and imidazole ligands are well known [7]. A large number of investigations on the complexation of copper(II) with imidazole ligands and vinylimidazole ligands have been reported, with some of them reporting structures determined crystallographically [20]. The title compound is a novel complex firstly synthesized by us.

Determination of the structural and spectroscopic properties of compounds using both experimental techniques and theoretical methods has attracted interest for many years. In recent years, among the computational methods calculating the electronic structure of molecular systems, DFT has been the favorite one due to its great accuracy in reproducing the experimental values of in molecule geometry, vibrational frequencies, atomic charges, dipole moment, and so forth $[21,22]$. 
In this present study, hexa(1-vinylimidazole) $\mathrm{Ni}(\mathrm{II})$ perchlorate has been investigated both experimentally and theoretically. In experimental study, the complex was synthesized and characterized by single-crystal X-ray diffraction methods. In theoretical study, the geometric parameters of the title complex in the ground state have been calculated using the density functional method (DFT) (UB3LYP) with 6-31G(d) and LanL2DZ basis sets. The calculated optimized structures were compared with their X-ray structure. It was noted here that the experimental results belong to solid phase and theoretical calculations belong to gaseous phase. In the solid state, the existence of the crystal field along with the intermolecular interactions has connected the molecules together, which result in the differences of bond parameters between the calculated and experimental values [23].

\section{Experimental and Theoretical Methods}

2.1. Reagents. Nickel(II) perchlorate hexahydrate $\left[\mathrm{Ni}\left(\mathrm{H}_{2} \mathrm{O}\right)_{6}\right]$ $\left(\mathrm{ClO}_{4}\right)_{2}$, 1-vinylimidazole, and ethanol were purchased from commercial sources and used without further purification. Perkin Elmer Diamond TG/DTA thermal analyzer was used to record simultaneous TG, DTG, and DTA curves in the static air atmosphere at a heating rate of $10 \mathrm{~K}$ min 21 in the temperature range $30-750^{\circ} \mathrm{C}$ using platinum crucibles.

2.2. Synthesis. Nickel(II) perchlorate hexahydrate (0.36 g; $1.0 \mathrm{mmol}$ ) was dissolved in $20 \mathrm{~mL}$ ethanol and 1-vinylimidazole $(0.56 \mathrm{~g} ; 6.0 \mathrm{mmol})$ was added slowly. The mixture was stirred for $1 \mathrm{~h}$, filtered, and left for crystallization. Single crystals of hexa(1-vinylimidazole) Ni(II) perchlorate suitable for X-ray analysis were obtained after one week (yield \%56).

2.3. Crystal Structure Analysis. Diffraction data for complex was collected on Agilent Diffraction SuperNova (single source at offset) Eos diffractometer using graphite monochromated Mo Ka radiation $(\lambda=0.71073 \AA)$ at $296 \mathrm{~K}$. The structure was solved by direct methods using SHELXS97 [24] and implemented in the WinGX [25] program suite. The refinement was carried out by full-matrix leastsquares method on the positional and anisotropic temperature parameters of the nonhydrogen atoms, or equivalently corresponding to 241 crystallographic parameters, using SHELXL-97 [26]. All H atoms were positioned geometrically and treated using a riding model, fixing the bond lengths at $0.86,0.93,0.97$, and $0.96 \AA$ for $\mathrm{NH}, \mathrm{CH}$, and $\mathrm{CH}_{2}$ atoms, respectively. All other $\mathrm{H}$ atoms were positioned geometrically and refined with a riding model with $\mathrm{U}_{\text {iso }} 1.2$ times that of attached atoms. Data collection is by CrysAlis PRO [27], cell refinement by CrysAlis RED [28], and data reduction by CrysAlis RED [28]. The general-purpose crystallographic tool PLATON [29] was used for the structure analysis and presentation of the results. Details of the data collection conditions and the parameters of the refinement process are given in Table 1 .
TABLE 1: Crystal data and structure refinement parameters for the title complex.

\begin{tabular}{|c|c|}
\hline Chemical formula & $\mathrm{C}_{30} \mathrm{H}_{36} \mathrm{~N}_{12} \mathrm{Ni} 2\left(\mathrm{ClO}_{4}\right)$ \\
\hline Formula weight & 822.32 \\
\hline Temperature (K) & 296 \\
\hline Wavelength $(\AA)$ & $0.71073 \mathrm{Mo} \mathrm{K} \alpha$ \\
\hline Crystal system & Monoclinic \\
\hline Space group & P 21/n \\
\hline \multicolumn{2}{|l|}{ Unit cell parameters } \\
\hline$a \neq b \neq c(\AA)$ & 8.442(5), 13.686(8), 16.041(9) \\
\hline$\beta\left(^{\circ}\right)$ & $96.638(5)$ \\
\hline Volume $\left(\AA^{3}\right)$ & $1840.85(18)$ \\
\hline$Z$ & 1 \\
\hline Calculated density $\left(\mathrm{Mg} / \mathrm{m}^{3}\right)$ & 1.484 \\
\hline$\mu\left(\mathrm{mm}^{-1}\right)$ & 0.74 \\
\hline$T_{\min }, T_{\max }$ & $0.882,1$ \\
\hline$F_{000}$ & 852 \\
\hline Crystal size (mm) & $0.1 \times 0.1 \times 0.1$ \\
\hline$h_{\min }, h_{\max }$ & $-6,10$ \\
\hline$k_{\min }, k_{\max }$ & $-16,14$ \\
\hline$l_{\min }, l_{\max }$ & $-19,19$ \\
\hline Theta range for data collection $\left({ }^{\circ}\right)$ & $3.2 \leq \theta \leq 26$ \\
\hline Measured reflections & 7193 \\
\hline Independent/observed reflections & 3525 \\
\hline Refinement method & Full-matrix least-squares on $F^{2}$ \\
\hline$w R\left(F^{2}\right)$ & 0.119 \\
\hline$R_{\mathrm{int}}$ & 0.036 \\
\hline$\Delta \rho_{\max }, \Delta \rho_{\min }\left(\mathrm{e} / \AA^{3}\right)$ & $0.51,-0.28$ \\
\hline
\end{tabular}

2.4. Computational Procedures. All the calculations were performed by using Gaussian 03 package [30] and GaussView molecular visualization programs [31] on the personal computer without restricting any symmetry for the title complex. For modeling, the initial guess of the complex was first obtained from the X-ray coordinates. The molecular structure of the title complex in the ground state (in vacuo) is optimized by UB3LYP methods with 6-31G(d) and LanL2DZ basis sets. Besides, the nonlinear optical effects, the molecular electrostatic potential (MEP), frontier molecular orbitals (FMO), and the Mulliken population analysis of the title complex were determined by theoretical calculation results.

\section{Results and Discussion}

3.1. Structural Description of the Complex. The title complex, a ORTEP-3 [32] view of which is shown in Figure 1, is crystallizing in the monoclinic space group P21/n with four molecules in unit cell. The asymmetric unit in the crystal structure contains the $\mathrm{Ni}$ (II) that is a cation, perchlorate anions, and six 1-vinylimidazole molecules. The $\mathrm{Ni}$ (II) atom displays a Jahn-Teller distorted octahedral coordination geometry, with six $\mathrm{N}$ atoms from six 1-vinylimidazole ligands in the equatorial plane and in axial positions. Ni-N1, Ni$\mathrm{N} 3$, and Ni-N5 bond lengths are 2.110(3) $\AA, 2.129(3) \AA$, and 2.125(3) $\AA$, respectively. These $\mathrm{Ni}-\mathrm{N}$ bond lengths are 


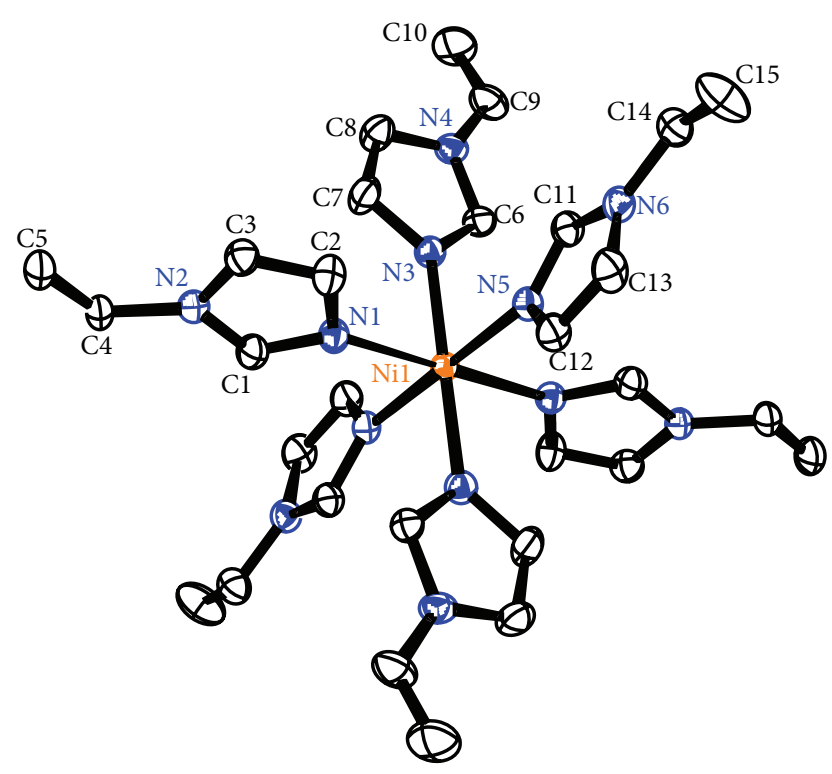

Figure 1: An ORTEP view of the title complex with the atomic numbering scheme. Displacement ellipsoids are shown at the $30 \%$ probability level.

TABle 2: Hydrogen bond geometry $\left(\AA{ }^{\circ}\right)$.

\begin{tabular}{lcccc}
\hline $\mathrm{D}-\mathrm{H} \cdots A$ & $\mathrm{D}-\mathrm{H}$ & $\mathrm{H} \cdots A$ & $\mathrm{D} \cdots A$ & $\mathrm{D}-\mathrm{H} \cdots A$ \\
\hline $\mathrm{C} 13-\mathrm{H} 13 \cdots \mathrm{O} 2^{\mathrm{a}}$ & 0.93 & 2.30 & $3.155(5)$ & 152 \\
$\mathrm{C} 2-\mathrm{H} 2 \cdots \mathrm{Cg}^{\mathrm{b}}$ & 0.93 & 2.74 & 3.4614 & 135 \\
\hline
\end{tabular}

Symmetry codes: ${ }^{\mathrm{a}} x-1 ; y-1 ; z ;{ }^{\mathrm{b}}-x ;-y+1 ;-z+1$.

$\mathrm{Cgl}$ is the centroid of the imidazole (N5, N6, C11-C13) ring.

comparable with those reported by $[33,34]$. When the bond lengths and angles of the imidazole rings in the title complex are compared with literature [35], it is seen that there are no significant differences.

The crystal packing is stabilized by a single intermolecular $\mathrm{C}-\mathrm{H}$... O hydrogen-bonding interaction (Table 2, Figure 2), giving a view of the crystal structure of complex approximately along the a axis. Also, in the structure, there is a $\mathrm{C} 2-$ $\mathrm{H} 2 \cdots \pi$ interaction between the $\mathrm{C} 2$ atom and imidazole (N5, N6, C11-C13) ring (symmetry code: (b) $-x,-y+1$, and $-z+1$ ). The distance of atom $\mathrm{C} 2$ between the centroids of these rings is $3.46 \mathrm{~A}$.

3.2. Magnetic Properties and Thermal Analysis. Magnetic moment determined for the hexa(1-vinylimidazole)Ni(II) perchlorate complex at room temperature is $2.90 \mathrm{BM}$. These values are characteristic of high-spin octahedral complexes of metals [36].

The thermal decomposition behavior of the complex was followed up to $750^{\circ} \mathrm{C}$ in a static air atmosphere. The complex is thermally stable up to $178^{\circ} \mathrm{C}$. The results of TGA/DTA curves of complex are illustrated in Figure 3. The TG curves exhibit a continuous mass loss. Therefore, it was almost impossible to calculate mass loss value for each step. The stages of the temperature range of $178-590^{\circ} \mathrm{C}$ are related to the repeatedly decomposition of the six 1-vinylimidazole

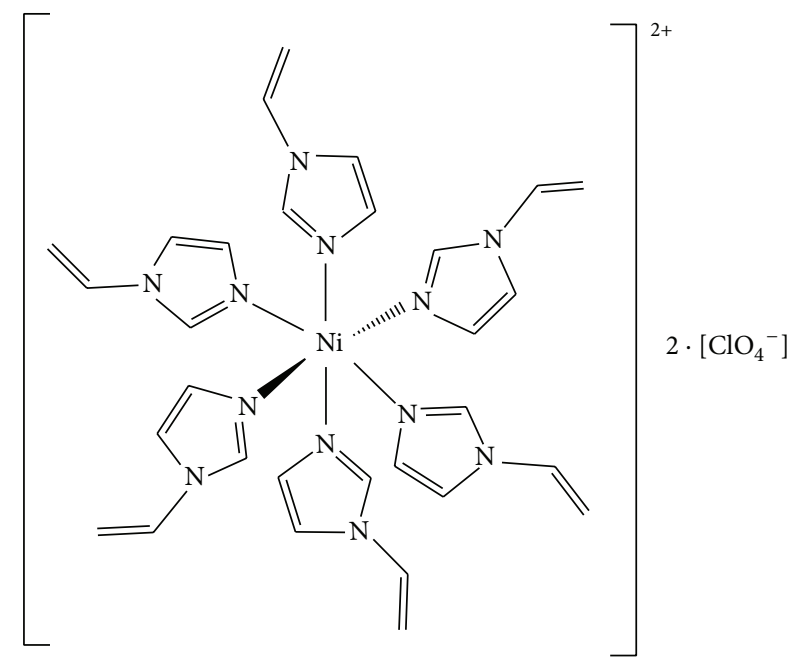

Scheme 1: The chemical diagram of the title complex.

ligands by giving both endo- and exothermic effects. The mass loss calculations suggest that the remainder is left as a final product. $\mathrm{NiO}$ is the end product (Teo: $11.1 \%$, exp: $12.2 \%)$

\subsection{Quantum Chemical Computational Studies}

3.3.1. Theoretical Structures. The molecular structure of the title complex was also investigated theoretically; see Scheme 1 . The starting coordinates were those obtained from the X-ray structure determination and in the ground state (in vacuo) was optimized using DFT(UB3LYP) with the 6$31 G(d)$ and LanL2DZ basis sets. However, it should not be forgotten in here that the experimental results belong to solid phase and theoretical calculations belong to gaseous phase. The optimized molecular structure of the title molecule was obtained from Gaussian 03 program as shown in Figure 4. The molecular structure of the complex belongs to $\mathrm{Cl}$ point group symmetry with 89 atoms composing the structure. Randomly selected geometric parameters (bond length, bond angle, and torsion angles) were experimentally obtained and theoretically calculated by UB3LYP methods with basis sets listed in Table 3 . And these selected parameters are compared with their experimental data. Correlation values $\left(R^{2}\right)$ are 0.9949 and 0.9881 for bond lengths, 0.9522 and 0.9994 for bond angles, and 0.1988 and 0.1043 for torsion angles, respectively. Consequently, according to correlations values, for the bond length and torsion angle, the 6-31G(d) basis set method is more useful than the LanL2DZ basis set method. Conversely, for bond angles, the LanL2DZ basis set method is more useful than the $6-31 G(\mathrm{~d})$ basis set method.

A logical method for globally comparing the structures obtained with the theoretical calculations is by superimposing the molecular skeleton with that obtained from X-ray diffraction, giving RMSEs of 0.084 and $0.071 \mathrm{~A}$ for the same methods, respectively. As a result, 6-31G(d) correlates a little well with the geometrical parameters when compared with LANL2Z method (Figure 5). 
TABLE 3: Randomly selected geometric parameters $\left(\AA,^{\circ}\right)$.

\begin{tabular}{|c|c|c|c|}
\hline \multirow{2}{*}{ Geometric parameters } & \multirow{2}{*}{$\begin{array}{l}\text { Experimental } \\
\text { (X-ray) }\end{array}$} & \multicolumn{2}{|c|}{ Calculated } \\
\hline & & $6-31 G(d)$ & LanL2DZ \\
\hline \multicolumn{4}{|l|}{ Bond lengths $(\AA)$} \\
\hline Ni1-N1 & $2.110(3)$ & 1.846 & 1.890 \\
\hline Nil-N3 & $2.129(3)$ & 1.838 & 1.890 \\
\hline Ni1-N5 & $2.125(3)$ & 1.894 & 1.990 \\
\hline $\mathrm{N} 1-\mathrm{C} 1$ & $1.310(4)$ & 1.337 & 1.354 \\
\hline $\mathrm{N} 1-\mathrm{C} 2$ & $1.373(4)$ & 1.397 & 1.415 \\
\hline N3-C6 & $1.309(4)$ & 1.335 & 1.353 \\
\hline $\mathrm{N} 3-\mathrm{C} 7$ & $1.376(4)$ & 1.397 & 1.415 \\
\hline N5-C11 & $1.306(4)$ & 1.326 & 1.338 \\
\hline N5-C12 & $1.377(4)$ & 1.389 & 1.405 \\
\hline $\mathrm{N} 2-\mathrm{C} 4$ & $1.418(4)$ & 1.396 & 1.405 \\
\hline N4-C9 & $1.418(4)$ & 1.395 & 1.405 \\
\hline N6-C14 & $1.423(4)$ & 1.400 & 1.414 \\
\hline $\mathrm{C} 2-\mathrm{C} 3$ & $1.339(5)$ & 1.361 & 1.377 \\
\hline C7-C8 & $1.345(5)$ & 1.360 & 1.377 \\
\hline $\mathrm{C} 12-\mathrm{C} 13$ & $1.341(4)$ & 1.363 & 1.380 \\
\hline \multicolumn{4}{|l|}{ Bond angles $\left({ }^{\circ}\right)$} \\
\hline N1-Ni1-N5 & $91.13(10)$ & 104.621 & 105.312 \\
\hline N5-Ni1-N3 & $89.24(10)$ & 106.220 & 104.813 \\
\hline $\mathrm{N} 1-\mathrm{C} 1-\mathrm{N} 2$ & $111.6(3)$ & 111.588 & 110.940 \\
\hline N3-C6-N4 & $112.3(3)$ & 111.626 & 110.952 \\
\hline N5-C11-N6 & $112.8(3)$ & 111.733 & 111.051 \\
\hline \multicolumn{4}{|l|}{ Torsion angles $\left({ }^{\circ}\right)$} \\
\hline $\mathrm{C} 5-\mathrm{C} 4-\mathrm{N} 2-\mathrm{C} 1$ & $-164.9(4)$ & 176.492 & -179.256 \\
\hline C10-C9-N4-C6 & $175.0(4)$ & 177.695 & -179.428 \\
\hline $\mathrm{C} 15-\mathrm{C} 14-\mathrm{N} 6-\mathrm{C} 11$ & $178.4(4)$ & 178.830 & 178.982 \\
\hline Ni1-N1-C1-N2 & $178.07(19)$ & 171.271 & 169.442 \\
\hline Ni1-N3-C6-N4 & $-179.3(2)$ & 171.464 & 169.024 \\
\hline Ni1-N5-C11-N6 & $-167.74(19)$ & -166.789 & -172.417 \\
\hline
\end{tabular}

3.3.2. Nonlinear Optical Effects. Nonlinear optical (NLO) effects arise from the interactions of electromagnetic fields in various media to produce new fields altered in phase, frequency, amplitude, or other propagation characteristics from the incident fields [37]. In the recent years, because of potential applications in modern communication technology, data storage, telecommunication, and optical signal processing, a large number of research papers in new materials exhibiting efficient nonlinear optical (NLO) properties have been of great interest [38-42].

The calculations of the mean linear polarizability $\left(\alpha_{\text {tot }}\right)$ and the mean first hyperpolarizability $\left(\beta_{\text {tot }}\right)$ from the Gaussian output have been explained in detail previously and DFT has been extensively used as an effective method to investigate the organic NLO materials [43]. The values of the polarizability $\alpha$ and the first hyperpolarizability $\beta$ of Gaussian
03 output are reported in atomic units (a.u.), so the calculated values have been converted into electrostatic units (esu) $(\alpha$ : 1 a.u. $=0.1482 \times 10^{-24}$ esu; $\beta$ : 1 a.u. $=8.6393 \times 10^{-33}$ esu).

The total molecular dipole moment $\left(\mu_{\mathrm{tot}}\right)$, linear polarizability $\left(\alpha_{\text {tot }}\right)$, and first-order hyperpolarizability $\left(\beta_{\text {tot }}\right)$ of the title compound were calculated with the UB3LYP/631G(d) and UB3LYP/LanL2DZ methods. The calculated values of $\mu_{\text {tot }}, \alpha_{\text {tot }}$, and $\beta_{\text {tot }}$ are $2.939 \mathrm{D}, 59.95 \mathrm{~A}^{3}$, and 69.86 $10^{-30} \mathrm{~cm}^{5} /$ esu for UB3LYP/6-31G(d) and $3.958 \mathrm{D}, 65.52 \mathrm{~A}^{3}$, and $278.110^{-30} \mathrm{~cm}^{5} /$ esu for UB3LYP/LanL2DZ, respectively. Urea is one of the prototypical molecules used in the study of the NLO properties of molecular systems. Therefore, it was used frequently as a threshold value for comparative purposes. Theoretically, the first-order hyperpolarizability of the title compound is of 12 and 14.4 times magnitude of urea at the same levels, respectively. According to these results, the title compound is a good candidate of NLO material.

3.3.3. Molecular Electrostatic Potential. The molecular electrostatic potential (MEP) is related to the electronic density and is a very useful descriptor in understanding sites for electrophilic attack and nucleophilic reactions as well as hydrogen-bonding interactions [44-46].

The molecular electrostatic potential, $V(r)$, at a given point $r(x, y, z)$ in the vicinity of a molecule is defined in terms of the interaction energy between the electrical charge generated from the molecule electrons and nuclei and a positive test charge (a proton) located at $r$. For the system studied, the $V(r)$ values were calculated as described previously using the following [47]:

$$
V(r)=\sum_{A} \frac{Z_{A}}{\left|R_{A}-r\right|}-\int \frac{\rho\left(r^{\prime}\right)}{\left|r^{\prime}-r\right|} d^{3} r^{\prime},
$$

where $Z_{A}$ is the charge of nucleus A located at $R_{A}, \rho\left(r^{\prime}\right)$ is the electronic density function of the molecule, and $r^{\prime}$ is the dummy integration variable. Being a real physical property, $V(r)$ can be determined experimentally by diffraction or by computational methods [48]. To predict reactive sites for electrophilic and nucleophilic attack for the title molecule, MEP was calculated at the 6-31G(d) and LanL2DZ optimized geometries. The negative (red) regions of MEP were related to electrophilic reactivity and the positive (blue) regions to nucleophilic reactivity shown in Figure 6. As can be seen from the figure, there is one possible site on the title complex for electrophilic attack. The negative region is localised on the carbon atom of the imidazole ring, $\mathrm{C13}$, with a maximum value of -0.049 and -0.064 a.u. for UB3LYP/6-31G(d) and UB3LYP/LanL2DZ basis sets. These results provide information concerning the region where the complex can interact intermolecularly and bond metallically. Therefore, Figure 6 confirms the existence of an intermolecular $\mathrm{C} 13-\mathrm{H} 13 \cdots \mathrm{O} 2$ interaction between the $\mathrm{O}$ atoms perchlorate ion and $\mathrm{C}$ atoms of the imidazole ring. 


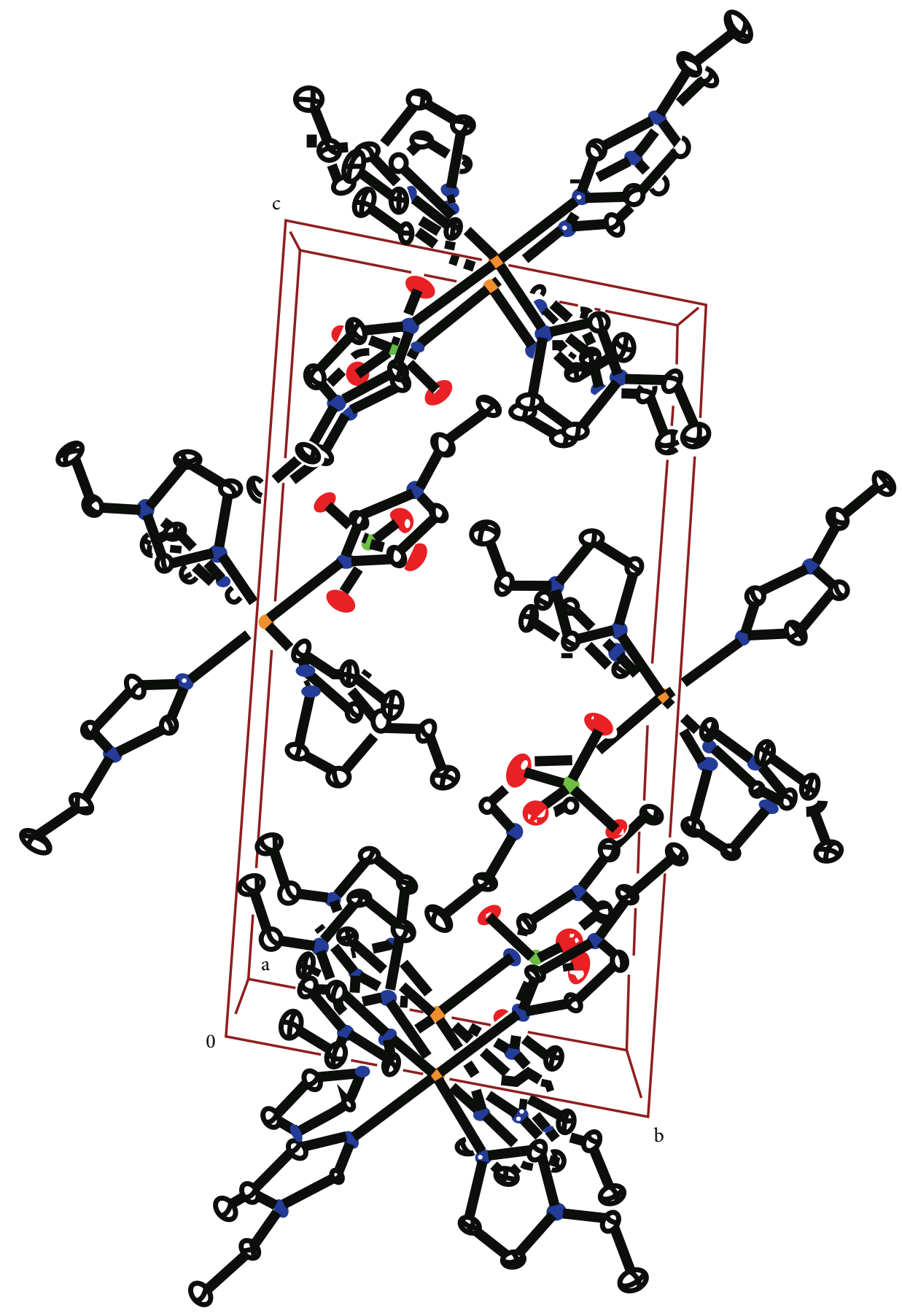

FIGURE 2: Part of the crystal packing of the title complex. For clarity, hydrogen atoms and hydrogen bonds are not shown.

3.3.4. HOMO-LUMO Analysis. The highest occupied molecular orbital (HOMO) and the lowest lying unoccupied molecular orbital (LUMO) are named as frontier molecular orbitals (FMO).

The distributions and energy levels of the HOMO and LUMO orbitals computed at the UB3LYP/6-31G(d) and UB3LYP/LanL2DZ level for the title complex are shown in Figure 7. The calculations indicate that the title complex has 89 and 84 occupied molecular orbitals and the value of the energy separation between the HOMO and LUMO are -1.5 and $-1.14 \mathrm{eV}$ for at the same levels, respectively.

A molecule with a small frontier orbital gap is more polarizable and is generally associated with a high chemical reactivity and low kinetic stability and is also termed as soft molecule [49]. The HOMO and LUMO energies, the energy gap $(\Delta E)$, the ionization potential $(I)$, the electron affinity $(A)$, the absolute electronegativity $(\chi)$, the absolute hardness $(\eta)$, and softness $(S)$ for molecule have been calculated at 


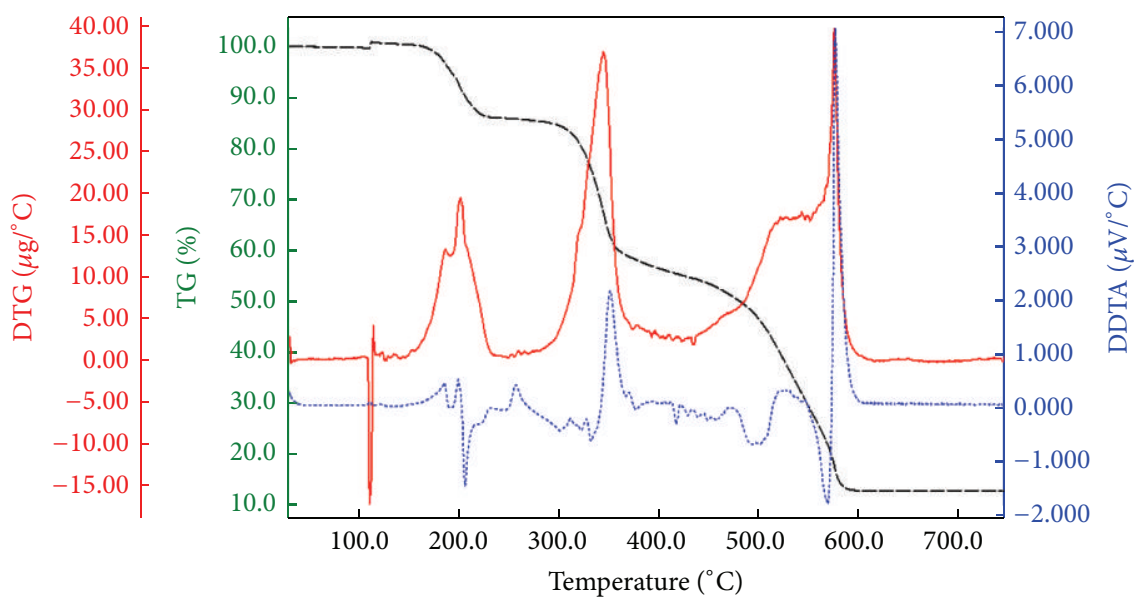

FIGURE 3: TGA/DTA curves of complex.

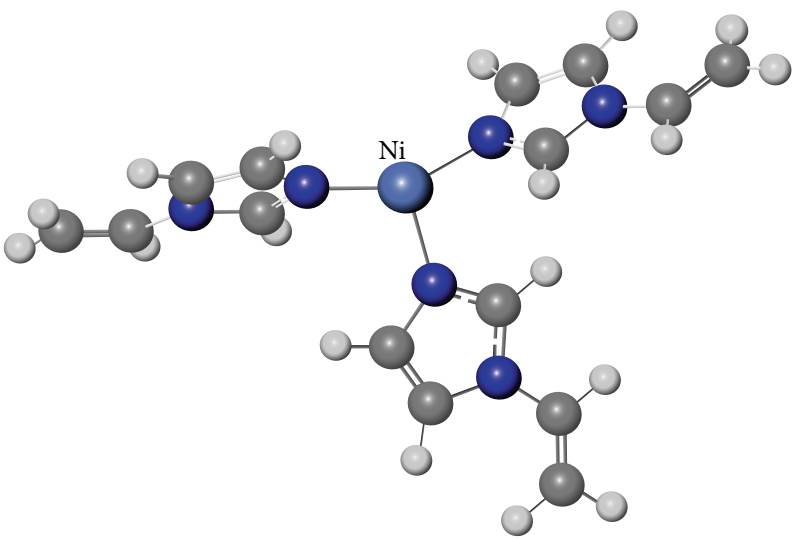

(a)

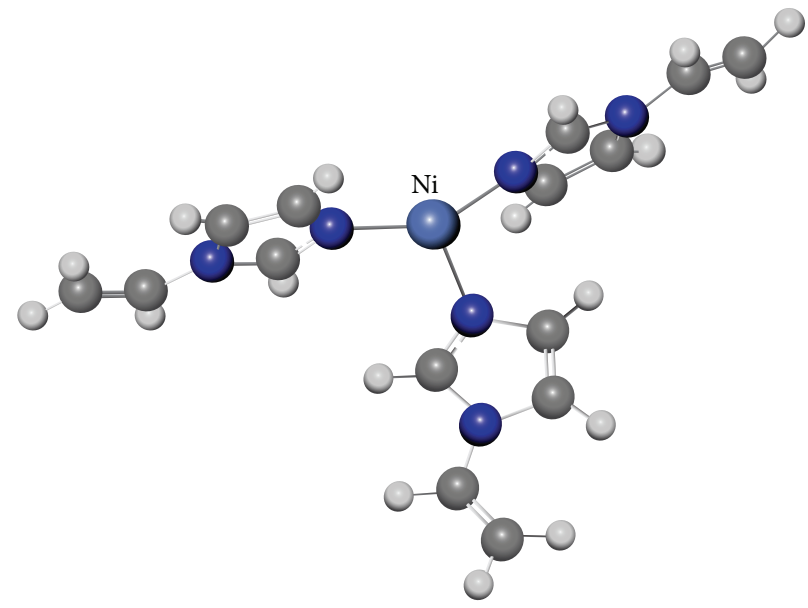

(b)

FIGURE 4: The theoretical geometric structures of the title compound ((a)= UB3LYP/6-31G(d), (b) = UB3LYP/LanL2DZ).

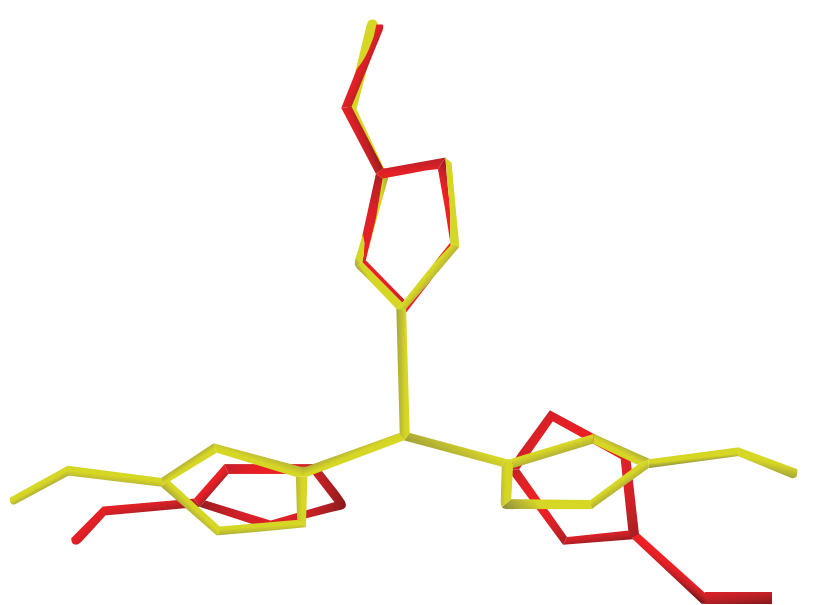

(a)

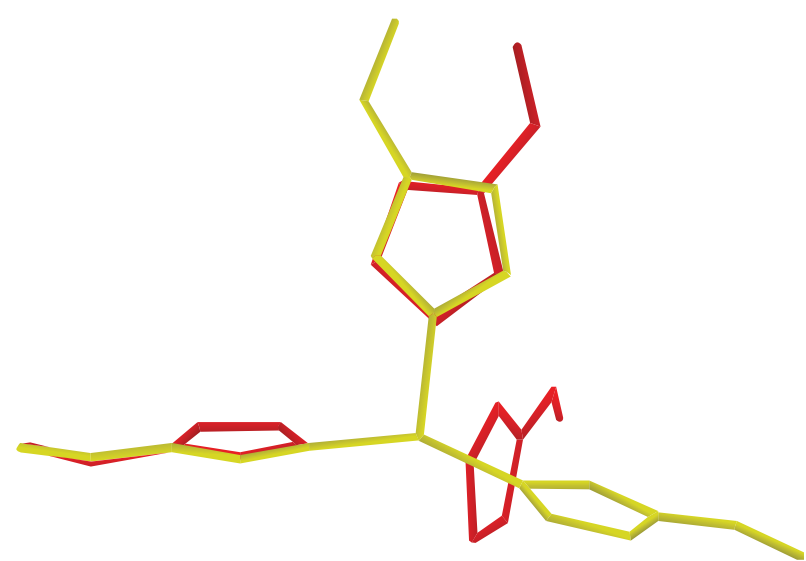

(b)

FIGURE 5: Atom-by-atom superimposition of the structures calculated (red) ((a) = UB3LYP/6-31G(d), (b) = UB3LYP/LanL2DZ) on the X-ray structure (yellow) of the title complex. Hydrogen atoms have been omitted for clarity. 


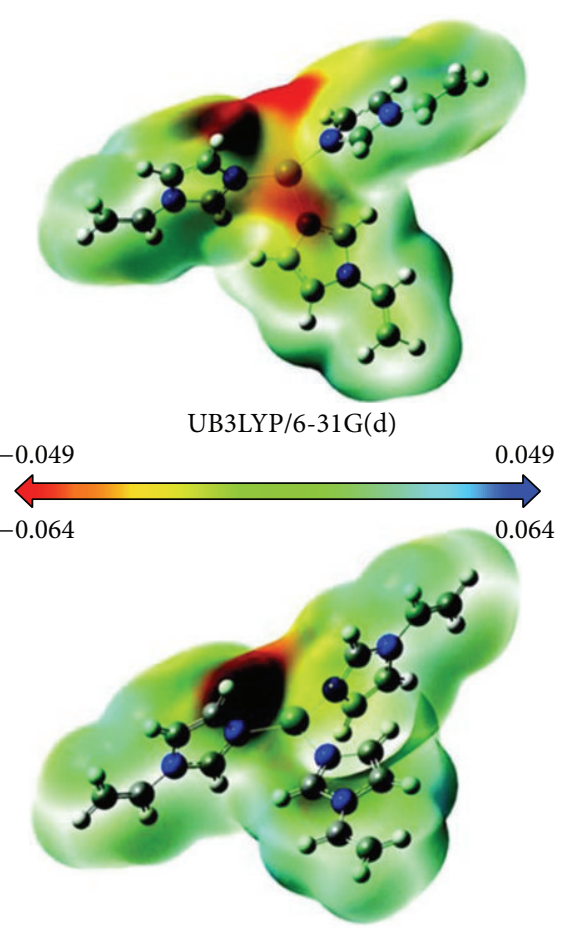

UB3LYP/LanL2DZ

FIGURE 6: Molecular electrostatic potential map (MEP) (in a.u.) calculated at UB3LYP/6-31G(d) and UB3LYP/LanL2DZ level frontier molecular orbitals analysis.

the same levels and the results are given in Table 4. By using HOMO and LUMO energy values for a molecule, electronegativity and chemical hardness can be calculated as follows: $\chi=(I+A) / 2$ (electronegativity), $\eta=(I-$ A) $/ 2$ (chemical hardness), and $S=1 / 2 \eta$ (chemical softness), where $I$ and $A$ are ionization potential and electron affinity, $I=-E_{\mathrm{HOMO}}$ and $A=-E_{\mathrm{LUMO}}$, respectively [50].

3.3.5. The Mulliken Charge Population. The Mulliken atomic charge calculation has an important role in the application of quantum chemical calculation to molecular system because of atomic charges effect dipole moment, molecular polarizability, electronic structure, and a lot of properties of molecular systems. The charge distributions calculated by the Mulliken method [51-54] for the equilibrium geometry of the complex is given in Figure 8. The calculated Mulliken charges of $\mathrm{C} 13$ and $\mathrm{H} 13$ atoms are determined as -0.12 and $0.16 \mathrm{e}$ and -0.21 and 0.26 e for the $6-31 G(d)$ and LanL2DZ methods, respectively. These values confirm intermolecular hydrogen bond $\mathrm{C} 13-\mathrm{H} 13 \cdots \mathrm{O} 2$.

\section{Conclusions}

In this present investigation, molecular structure, nonlinear optical effects, molecular electrostatic potential, HOMOLUMO analysis, and the Mulliken charge populations of hexa(1-vinylimidazole)Ni(II) perchlorate have been studied

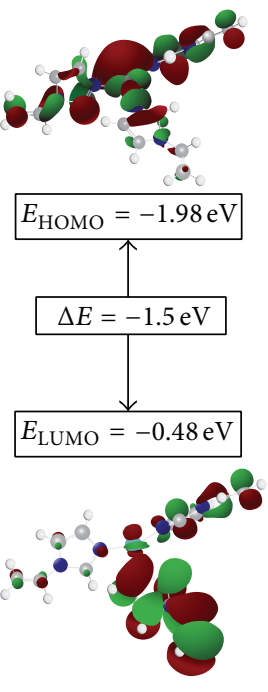

UB3LYP/6-31G(d)
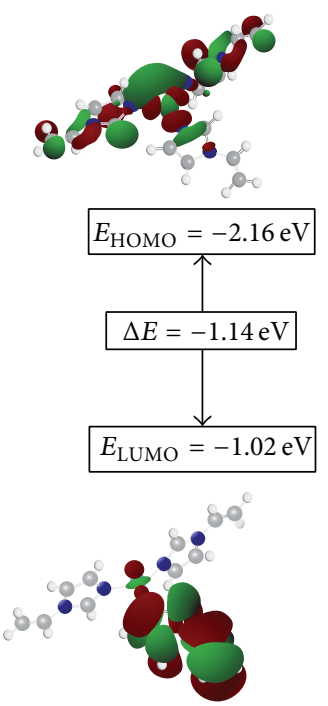

UB3LYP/LanL2DZ
Figure 7: The distributions and energy levels of the HOMO and LUMO orbitals computed at the UB3LYP/6-31G(d) and UB3LYP/LanL2DZ levels for the title complex.

TABLE 4: The calculated frontier orbital energies, electronegativity, hardness, and softness of complex using UB3LYP/6-31G(d) and UB3LYP/LanL2DZ levels.

\begin{tabular}{lcc}
\hline & $6-31 \mathrm{G}(\mathrm{d})$ & LanL2DZ \\
\hline$E_{\text {HOMO }}(\mathrm{eV})$ & -1.98 & -2.16 \\
$E_{\mathrm{LUMO}}(\mathrm{eV})$ & -0.48 & -1.02 \\
$I(\mathrm{eV})$ & 1.98 & 2.16 \\
$A(\mathrm{eV})$ & 0.48 & 1.02 \\
$\chi(\mathrm{eV})$ & 1.23 & 1.59 \\
$\eta(\mathrm{eV})$ & 0.75 & 0.57 \\
$S\left(\mathrm{eV}^{-1}\right)$ & 0.66 & 0.87 \\
\hline
\end{tabular}

using DFT (UB3LYP/6-31G(d) and UB3LYP/LanL2DZ) calculations. They are compared with the calculated geometric parameters (bond lenght, bond angle, and torsion angle) with their experimental data. It is seen that there are no significant differences, when the experimental structure is compared with theoretical structures. It was noted here that the experimental results belong to solid phase and theoretical calculations belong to gaseous phase. The predicted nonlinear optical (NLO) properties of the complex are much greater than those of urea. The complex is a good candidate as second-order nonlinear optical material. Besides, The MEP map shows that the negative potential sites are on electronegative atoms and the positive potential sites are around the hydrogen atoms. These sites provide information concerning the region from where the compound can undergo intra- and intermolecular interactions. Similarly, the Mulliken charges confirm the intermolecular hydrogen bonds in the crystal. 


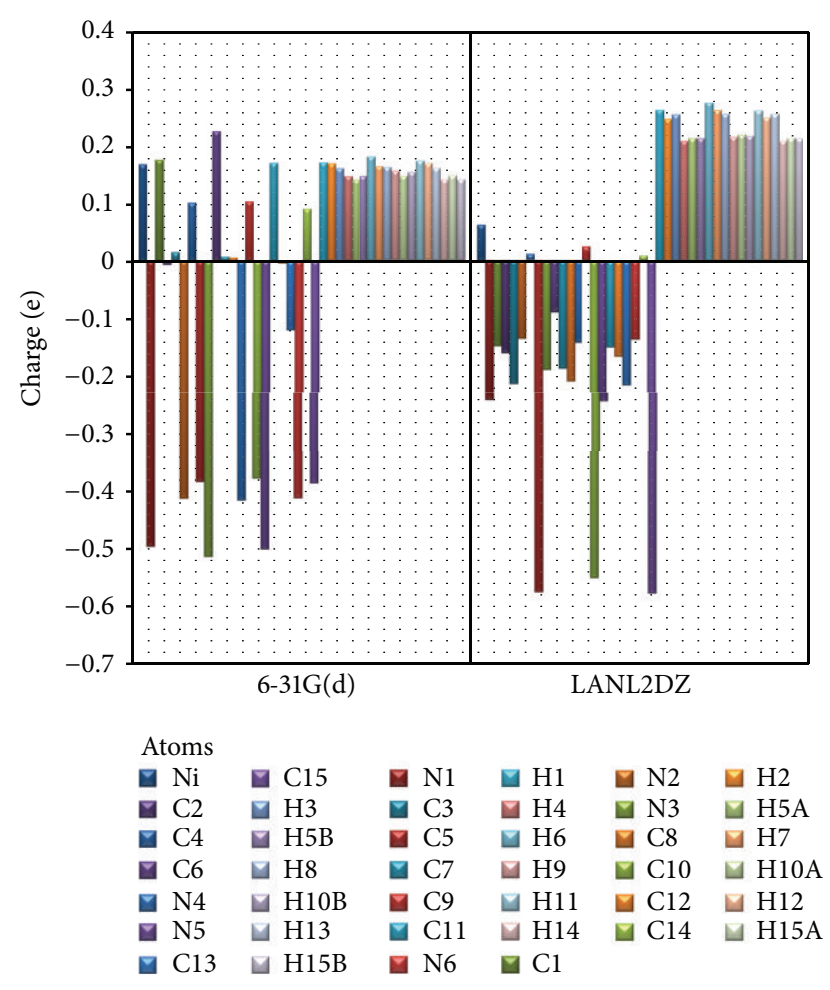

FIgURE 8: The charge distribution calculated by the Mulliken method for complex.

\section{Disclosure}

Supplementary file (crystallographic data) for the structure reported in this paper has been deposited with the Cambridge Crystallographic Data Center as Supplementary Publication no. CCDC-940965. Copies of the data can be obtained free of charge on application to CCDC, 12 Union Road, Cambridge CB2 1EZ, UK (fax: (+44)1223 336-033; e-mail: deposit@ccdc.cam.ac.uk).

\section{Conflict of Interests}

The authors declare that there is no conflict of interests regarding the publication of this paper.

\section{Acknowledgment}

This work was supported by TÜBİTAK-The Scientific and Technological Research Council of Turkey (Project no. 110T131).

\section{References}

[1] http://en.wikipedia.org/wiki/Imidazole.

[2] K. Kurdziel and T. Glowiak, "Palladium(II) complexes of 1vinylimidazole," Journal of Coordination Chemistry, vol. 55, no. 3, pp. 327-334, 2002.

[3] S. Yoshida and H. Ishida, "A study on the orientation of imidazoles on copper as corrosion inhibitor and possible adhesion promoter for electric devices," The Journal of Chemical Physics, vol. 78, no. 11, pp. 6960-6969, 1983.

[4] S. Yoshida and H. Ishida, "A FT-IR reflection-absorption spectroscopic study of an epoxy coating on imidazole-treated copper," Journal of Adhesion, vol. 16, no. 3, pp. 217-232, 1984.

[5] N. K. Tatel, J. Franco, and I. S. Patel, "Corrosion of 63/37 brass in citric acid solution and its inhibition by azole-type compounds," Journal of the Indian Chemical Society, vol. 54, pp. 815-816, 1977.

[6] L. Shargel, A. H. Mutnick, P. F. Souney, and L. N. Swanson, Comprehensive Pharmacy Review, Lippincott Williams \& Wilkins, 6th edition, 2006.

[7] R. J. Sundberg and R. B. Martin, "Interactions of histidine and other imidazole derivatives with transition metal ions in chemical and biological systems," Chemical Reviews, vol. 74, no. 4, pp. 471-517, 1974.

[8] G. Challa, J. Reedijk, and P. W. N. M. van Leeuwen, "Macromolecular metal complexes as catalysts with improved stability," Polymers for Advanced Technologies, vol. 7, no. 8, pp. 625-633, 1996.

[9] C. G. Overberger and R. Tomko, "Catalysis by water-soluble imidazole-containing polymers," ACS Symposium Series, vol. 212, pp. 13-21, 1983.

[10] M. Suzuki, S. Kobayashi, T. Koyama et al., "Kinetics of intrapolymer electron-transfer reactions in macromolecule-metal complexes," Journal of the Chemical Society, Faraday Transactions, vol. 91, no. 17, pp. 2877-2880, 1995.

[11] G. Manecke and R. Schlegel, "Polymere imidazolcarbonsäuren, 2. Über das schwermetallionenbindungsvermögen von chelatharzen mit 4,5-sicarboxyimidazolyl-gruppen," Macromolecular Chemistry, vol. 179, pp. 19-27, 1978.

[12] J. Wang and C. Chen, "Biosorbents for heavy metals removal and their future," Biotechnology Advances, vol. 27, no. 2, pp. 195226, 2009.

[13] S. Pramanik, S. Dhara, S. S. Bhattacharyya, and P. Chattopadhyay, "Separation and determination of some metal ions on new chelating resins containing N, N donor sets," Analytica Chimica Acta, vol. 556, no. 2, pp. 430-437, 2006.

[14] B. L. Rivas, M. Jara, and E. D. Pereira, "Preparation and adsorption properties of the chelating resins containing carboxylic, sulfonic, and imidazole groups," Journal of Applied Polymer Science, vol. 89, no. 10, pp. 2852-2856, 2003.

[15] M. D. Green and T. E. Long, "Designing imidazole-based ionic liquids and ionic liquid monomers for emerging technologies," Polymer Reviews, vol. 49, pp. 291-314, 2009.

[16] M. R. Grimmett, "Imidazoles," in Comprehensive Heterocyclic Chemistry II, A. R. Katritzky, C. W. Ress, and E. F. V. Scriven, Eds., vol. 3, pp. 77-220, Pergamon Press, Oxford, UK, 1996.

[17] M. R. Grimmett, Imidazoleand Benzimidazole Synthesis, Academic Press, New York, NY, USA, 1997.

[18] M. R. Grimmett, "Advances in imidazole chemistry," Advances in Heterocyclic Chemistry, vol. 12, pp. 103-183, 1970.

[19] A. Novelli and A. de Santis, "General synthesis of C substituted imidazoles," Tetrahedron Letters, vol. 8, no. 3, pp. 265-269, 1967.

[20] Y. Kurimura, T. Abe, Y. Usui, E. Tsuchida, H. Nishide, and G. Challa, "Characteristic behaviour of the complexation of copper(II) with polymer-bound vinylimidazole ligands," Journal of the Chemical Society, Faraday Transactions, vol. 90, no. 23, pp. 3563-3566, 1994.

[21] T. Ziegler, "Density functional theory as a practical tool for the study of elementary reaction steps in organometallic chemistry," Pure and Applied Chemistry, vol. 63, pp. 873-878, 1991. 
[22] P. M. W. Gill, B. G. Johnson, J. A. Pople, and M. J. Frisch, "The performance of the Becke-Lee-Yang-Parr (B-LYP) density functional theory with various basis sets," Chemical Physics Letters, vol. 197, no. 4-5, pp. 499-505, 1992.

[23] F. F. Jian, P. S. Zhao, Z. S. Bai, and L. Zhang, "Quantum chemical calculation studies on 4-phenyl-1-(propan-2- ylidene)thiosemicarbazide," Structural Chemistry, vol. 16, no. 6, pp. 635-639, 2005.

[24] G. M. Sheldrick, SHELXL 97, Program for the Solution of Crystal Structures, University of Göttingen, Göttingen, Germany, 1997.

[25] L. J. Farrugia, "Win $G X$ suite for small-molecule single-crystal crystallography," Journal of Applied Crystallography, vol. 32, no. 4, pp. 837-838, 1999.

[26] G. M. Sheldrick, SHELXL-97, Program for Crystal Structures Refinement, University of Göttingen, Göttingen, Germany, 1997.

[27] CrysAlis PRO, Oxford Diffraction, Abingdon, Oxfordshire, UK, 2007.

[28] CrysAlis RED, Oxford Diffraction, Abingdon, Oxfordshire, UK, 2007.

[29] A. L. Spek, "Structure validation in chemical crystallography," Acta Crystallographica D, vol. 65, no. 2, pp. 148-155, 2009.

[30] M. J. Frisch, G. W. Trucks, H. B. Schlegel et al., Gaussian 03, Revision E.01, Gaussian, Inc., Wallingford, Conn, USA, 2004.

[31] R. Dennington II, T. Keith, and J. Millam, Gauss View, Version 4.1.2, Semichem Inc., Shawnee Mission, Kan, USA, 2007.

[32] L. J. Farrugia, "ORTEP-3 for Windows-a version of ORTEPIII with a Graphical User Interface (GUI)," Journal of Applied Crystallography, vol. 30, p. 565, 1997.

[33] N. Şireci, Ü. Yılmaz, H. Küçükbay et al., "Synthesis of 1substituted benzimidazole metal complexes and structural characterization of dichlorobis(1-phenyl-1 $H$-benzimidazole$\kappa N^{3}$ )cobalt(II) and dichlorobis (1-phenyl-1 $H$-benzimidazole$\kappa N^{3}$ )zinc(II)," Journal of Coordination Chemistry, vol. 64, no. 11, pp. 1894-1902, 2011.

[34] M. Akkurt, S. Karaca, H. Küçükbay, E. Orhan, and O. Büyükgüngör, "Dichlorobis[1-(2-ethoxyethyl)-1H-benzimidazole- $\left.\kappa N^{3}\right]$ nickel(II)," Acta Crystallographica E, vol. 61, pp. m41$\mathrm{m} 43,2005$.

[35] F. Şen, R. Şahin, Ö. Andaç, and M. Taş, "trans-Bis(nitrato$\kappa O)$ tetrakis(1-vinyl-1H-imidazole- $\left.\kappa N^{3}\right)$ copper(II)," Acta Crystallographica E, vol. 68, p. m1045, 2012.

[36] A. B. P. Lever, Inorganic Electronic Spectroscopy, Elsevier, Amsterdam, The Netherlands, 1984.

[37] Y.-X. Sun, Q.-L. Hao, W.-X. Wei et al., "Experimental and density functional studies on 4-(3,4-dihydroxybenzylideneamino) antipyrine, and 4-(2,3,4-trihydroxybenzylideneamino)antipyrine," Journal of Molecular Structure: THEOCHEM, vol. 904, no. 1-3, pp. 74-82, 2009.

[38] R. Zhang, B. Du, G. Sun, and Y. Sun, "Experimental and theoretical studies on o-, $\mathrm{m}$ - and p-chlorobenzylideneaminoantipyrines," Spectrochimica Acta A, vol. 75, no. 3, pp. 1115-1124, 2010.

[39] S. Yazıcı, Ç. Albayrak, I. Gümrükçüoğlu, I. Şenel, and O. Büyükgüngör, "Experimental and density functional theory (DFT) studies on (E)-2-acetyl-4-(4-nitrophenyldiazenyl) phenol," Journal of Molecular Structure, vol. 985, no. 2-3, pp. 292298, 2011.

[40] D. S. Chemia and J. Zyss, Non Linear Optical Properties of Organic Molecules and Crystal, Academic Press, New York, NY, USA, 1987.
[41] J. Zyss, Molecular Non Linear Optics, Academic Press, Boston, Mass, USA, 1994.

[42] A. Ben Ahmed, H. Feki, Y. Abid, and C. Minot, "Molecular structure, vibrational spectra and nonlinear optical properties of orthoarsenic acid-tris-(hydroxymethyl)-aminomethane DFT study," Spectrochimica Acta A, vol. 75, no. 4, pp. 1315-1320, 2010.

[43] G. A. Babu and P. Ramasamy, "Growth and characterization of an organic NLO material ammonium malate," Current Applied Physics, vol. 10, no. 1, pp. 214-220, 2010.

[44] E. Scrocco and J. Tomasi, "Electronic molecular structure, reactivity and intermolecular forces: an euristic interpretation by means of electrostatic molecular potentials," Advances in Quantum Chemistry, vol. 11, pp. 115-193, 1979.

[45] F. J. Luque, J. M. López, and M. Orozco, "Perspective on "Electrostatic interactions of a solute with a continuum. A direct utilization of ab initio molecular potentials for the prevision of solvent effects"', Theoretical Chemistry Accounts, vol. 103, no. 34, pp. 343-345, 2000.

[46] N. Okulik and A. H. Jubert, "Theoretical analysis of the reactive sites of non-steroidal anti-inflammatory drugs," Internet Electronic Journal of Molecular Design, vol. 4, pp. 17-30, 2005.

[47] P. Politzer and J. S. Murray, "The fundamental nature and role of the electrostatic potential in atoms and molecules," Theoretical Chemistry Accounts, vol. 108, no. 3, pp. 134-142, 2002.

[48] P. Politzer and D. G. Truhlar, Chemical Applications of Atomic and Molecular Electrostatic Potentials, Plenum, New York, NY, USA, 1981.

[49] I. Fleming, Frontier Orbitals and Organic Chemical Reactions, John Wiley \& Sons, London, UK, 1976.

[50] R. G. Pearson, "Absolute electronegativity and hardness correlated with molecular orbital theory," Proceedings of the National Academy of Sciences of the United States of America, vol. 83, no. 22, pp. 8440-8841, 1986.

[51] R. S. Mulliken, "Electronic population analysis on LCAO-MO molecular wave functions. I," The Journal of Chemical Physics, vol. 23, no. 10, pp. 1833-1840, 1955.

[52] R. S. Mulliken, "Electronic population analysis on LCAOMO molecular wave functions. II. Overlap populations, bond orders, and covalent bond energies," The Journal of Chemical Physics, vol. 23, no. 10, pp. 1841-1846, 1955.

[53] R. S. Mulliken, "Electronic population analysis on LCAOMO molecular wave functions. III. effects of hybridization on overlap and gross AO populations," The Journal of Chemical Physics, vol. 23, no. 12, pp. 2338-2342, 1955.

[54] R. S. Mulliken, "Electronic population analysis on LCAO-MO molecular wave functions. IV. bonding and antibonding in LCAO and valence-bond theories," The Journal of Chemical Physics, vol. 23, no. 12, pp. 2343-2346, 1955. 

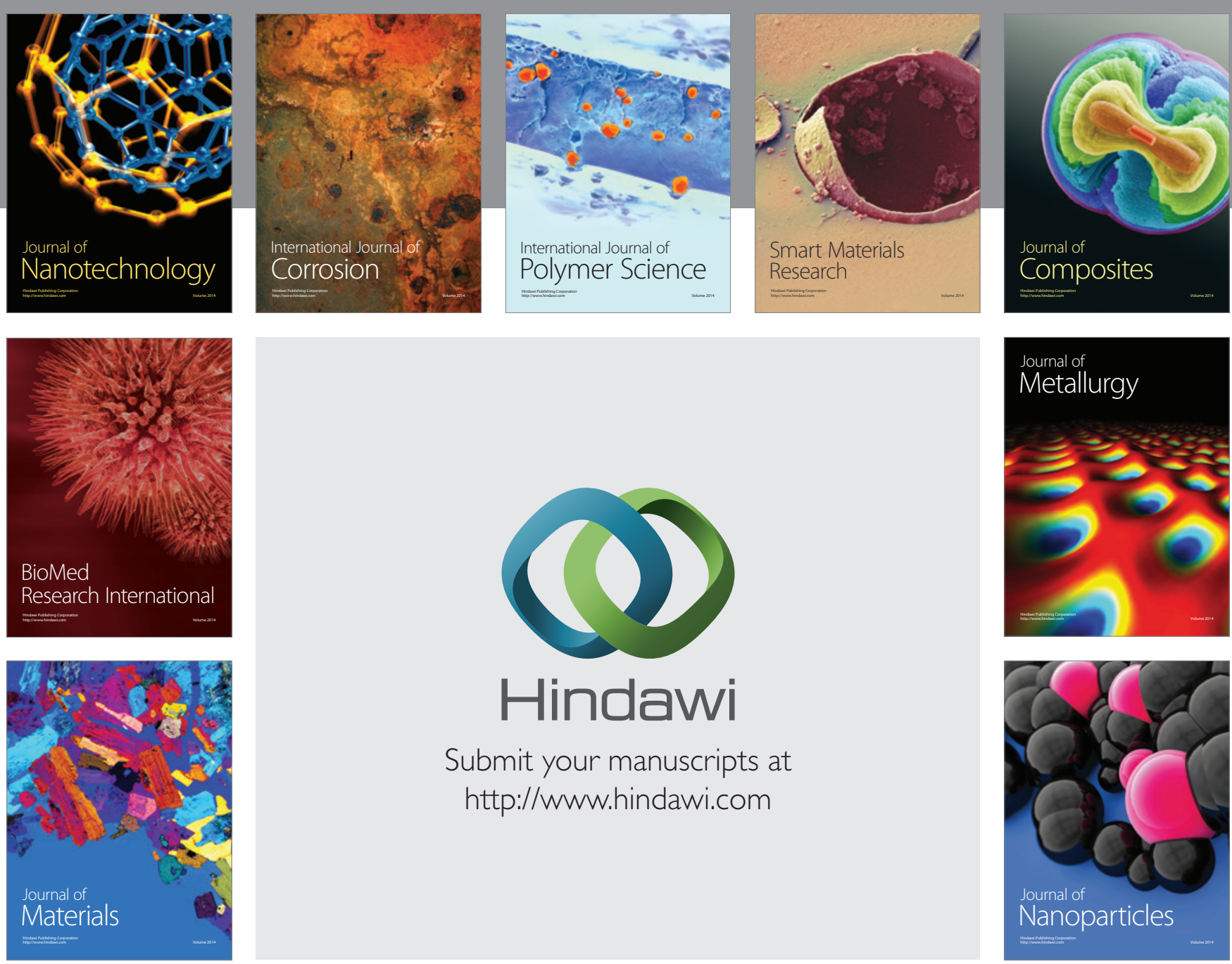

Submit your manuscripts at http://www.hindawi.com
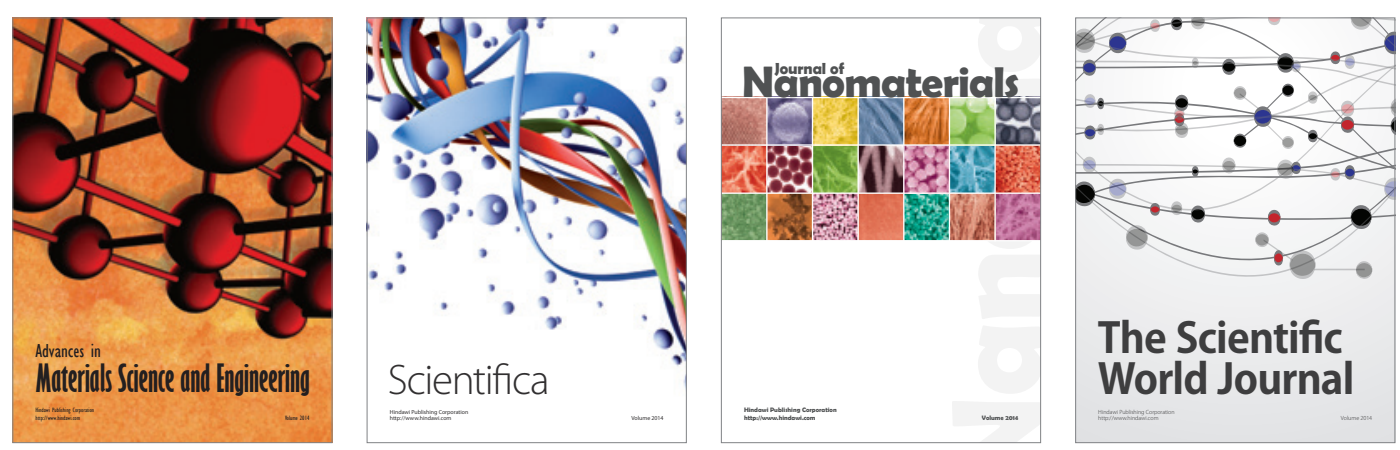

\section{The Scientific World Journal}
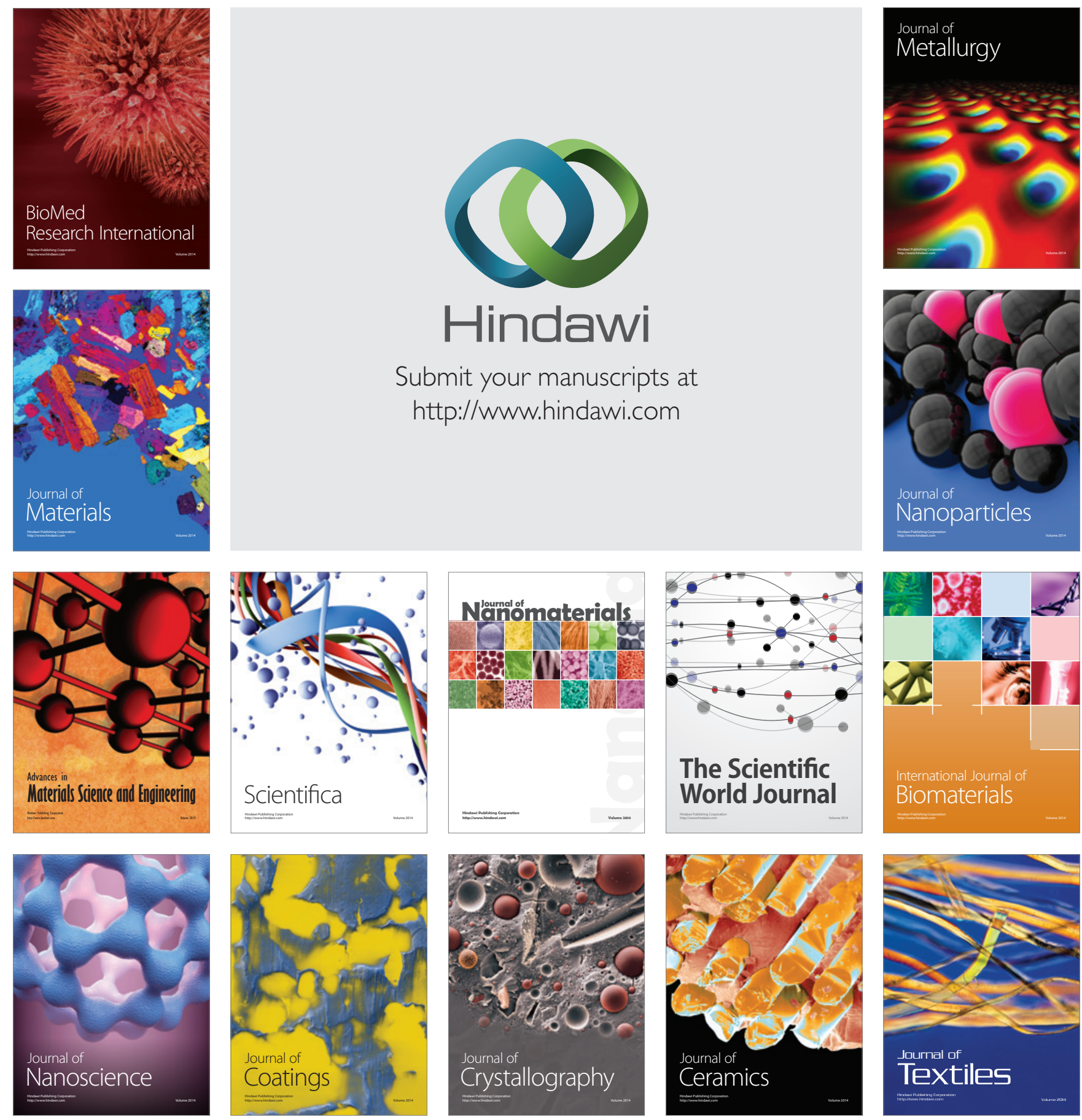